\title{
ALL-CELLULOSE COMPOSITE FROM COTTON FABRIC AND CELLULOSE SOLUTION
}

\author{
NASHRAH H. KIDWAI, HARWINDER SINGH and AROBINDO CHATTERJEE \\ Department of Textile Technology, Dr. B. R. Ambedkar National Institute of Technology, \\ Jalandhar, Punjab 144011, India \\ \Corresponding author: A. Chatterjee, chatterjeea@nitj.ac.in
}

Received February 20, 2020

\begin{abstract}
A cotton fabric reinforced all-cellulose composite (ACC) has been prepared by impregnation of fabric in dissolved cellulose solution. The solution was prepared by dissolving viscose fibres in $\mathrm{NaOH} / \mathrm{urea}$ solvent at low temperature. In the processing of composite preparation, three process parameters, i.e., pressure $\left(\mathrm{kg} / \mathrm{cm}^{2}\right)$, time (s) and viscose fibre concentration (\%), were considered, analyzed by the Box-Behnken design and optimized to study their effect on the weave types of fabric (plain, twill and satin). The characterization of the composite samples was carried out using SEM, XRD, FTIR and tensile tests. Changes in crystallite size and crystallinity were recorded after the treatment. No significant change in tenacity was observed, however a $49.56 \%$ increase in elongation in the case of plain ACC, $58.40 \%$ for twill ACC and $25.61 \%$ for satin ACC was observed. The tearing strength reduced by $15.50 \%, 28.77 \%$ and $30.54 \%$ for plain, twill and satin ACC, respectively, while stiffness reduced by $16.18 \%, 10.34 \%$ and $10.16 \%$, respectively.
\end{abstract}

Keywords: all-cellulose composite, cotton fabric, $\mathrm{NaOH}$-urea solvent system, mechanical properties, WAXD, FTIR

\section{INTRODUCTION}

Composites are produced from two components: a matrix and a reinforcement, to improve the overall properties of the composite structure. Usually, the reinforcement plays an important role and the type of reinforcement used mostly classifies composites. There is a wide range of end uses of composites prepared from glass or carbon fibres reinforced epoxy resin or unsaturated polyester, due to their excellent mechanical and thermal properties. ${ }^{1}$ However, apart from these advantages, some environmental problems, particularly related to disposal after their life cycle, are associated with such products. The exhaustive use of petroleum based resources has motivated efforts to develop new biodegradable composites. ${ }^{2}$ Today, there is a growing demand for environment-friendly composites that can help to overcome these problems.

The fabrication of natural fibre reinforced polymer composites has a major weakness arising from poor interfacial adhesion. This limitation can be resolved by the development of a unipolymer composite, consisting of components of similar chemical composition. When manufacturing mono-component composites using synthetic fibres, problems related to overheating and loss of characteristics during processing of melted matrix have been reported. Such problems can be avoided by using cellulose, which is known not to melt. ${ }^{1}$ In addition to this advantage, cellulose presents excellent mechanical properties and low density, low cost, renewability and biodegradability.

There are several processing routes for manufacturing all-cellulose composites, along with various cellulose resources and solvents for cellulose dissolution. Cellulose reinforcement can be mixed with a pre-dissolved cellulose solution, which forms the matrix, or the cellulosic substrate is brought into contact with a solvent, leading to partial dissolution and thereby creating a cellulose matrix in situ. ${ }^{3}$ The properties of ACCs obtained by partial dissolution of cellulose depend upon the amounts of cellulose I and cellulose $\mathrm{II}^{4}{ }^{4}$ Monocomponent composites can also be prepared by a technique in which the cellulose matrix is dissolved and then precipitated, while the reinforcement is undissolved or partly-dissolved cellulose. Matrix properties are governed by the 
rate of precipitation. ${ }^{5,6}$ Partial dissolution of crystalline cellulose has been explored in some studies to overcome the issues of a highly viscous fully-dissolved matrix. Due to improved chemical compatibility between the matrix and the reinforcement, some of the ACCs exhibit mechanical properties superior to those of cellulose-reinforced thermoplastics.

Most of the studies reported so far are based on an approach consisting in a one-step process of selective or partial dissolution of cellulose and subsequent regeneration of the dissolved component. In the present study, ACCs are developed with a typical two-step process of composite formation, in which the matrix phase is prepared separately by dissolving cellulose with a lower degree of polymerization (DP) (viscose), and then the filler phase is impregnated with a higher DP cellulose matrix (cotton fabric). After impregnation, the cellulose from the dissolved phase is regenerated in the composite, with the consideration that the filler will be relatively unaffected by the solvent. Low DP viscose is chosen deliberately, as higher DP and crystallinity decrease the solubility of cellulose. ${ }^{7}$ The ACCs have been developed with the aim to eliminate the chemical incompatibilities between reinforcement and matrix phases by utilizing cellulose for both components. Numerous known non-derivatising solvents for cellulose dissolution are available, but here $\mathrm{NaOH} / \mathrm{urea}$ is used due to its low environmental impact and low cost. ${ }^{8}$ Apart from $\mathrm{NaOH}$, the use of additives, such as urea and $\mathrm{ZnO}$, has been found to increase the solubility of cellulose and the stability of solutions. ${ }^{6}$ Limited dissolution capacity, slow dissolution rates, toxicity and non-recyclability prevent many solvents from being used on a large industrial scale. An improvement in cellulose dissolution with a decrease in temperature due to the formation of an inclusion complex between cellulose, $\mathrm{NaOH}$ and urea hydrates has been reported in the literature. Urea does not directly interact with the cellulose, but it forms a hydration coat around the dissolved chains. ${ }^{4}$

\section{EXPERIMENTAL Material}

Three different types of cotton fabrics spun from $20 \mathrm{~s} \mathrm{Ne}$ Rotor yarn were used as reinforcement for ACC, while viscose fibre dissolved in $\mathrm{NaOH} /$ urea solvent was used as matrix. As the fabrics were used as filler, the effect of fabric structure on the properties of resultant composites was also investigated. The specifications of the fabrics are given in Table 1.

\section{Preparation of ACCs}

The solvent was prepared by mixing $7 \mathrm{wt} \% \mathrm{NaOH}$, $12 \mathrm{wt} \%$ urea and $81 \mathrm{wt} \%$ distilled water, with the material to liquor ratio (MLR) of 1:30, under constant stirring at room temperature until a clear solution was obtained. ${ }^{4}$ The $\mathrm{NaOH} /$ urea solvent prepared was cooled down to $-12{ }^{\circ} \mathrm{C}$. Viscose fibres were dissolved in the solvent to prepare a cellulose solution of varying concentration $(0.5 \%, 1 \%$ and $1.5 \%)$. For the preparation of ACCs, cotton fabrics were dipped in the above solution for different dipping times $(60 \mathrm{~s}, 90 \mathrm{~s}$, $120 \mathrm{~s})$ and then passed through a padding mangle at three different pressures $\left(1 \mathrm{~kg} / \mathrm{cm}^{2}, 1.5 \mathrm{~kg} / \mathrm{cm}^{2}, 2\right.$ $\left.\mathrm{kg} / \mathrm{cm}^{2}\right){ }^{2}$ Impregnated fabrics were washed with water to facilitate coagulation and regeneration of dissolved cellulose. ${ }^{5}$ Repeated washing of the samples was done until a neutral $\mathrm{pH}$ was obtained to ensure complete removal of residual chemicals. ${ }^{6}$

\section{Design of experiment}

Three numerical parameters, i.e., padding mangle pressure $\left(\mathrm{kg} / \mathrm{cm}^{2}\right)$, time of impregnation (s) and concentration of cellulose solution (\%), and three categorical parameters (plain, twill and satin weave) were considered in designing the experiments. The Box-Behnken response surface design was employed to investigate the effects of process parameters and for optimization of process parameters for processing categorical factors. The parameters and their levels are shown in Table 2. The levels of process parameters were selected based on the literature survey and experimental observations. ${ }^{9}$

Table 1

Fabric specifications

\begin{tabular}{lcccc}
\hline Type & G.S.M. & E.P.I. & P.P.I. & Thickness (mm) \\
\hline Plain weave & 177 & 113 & 57 & 0.28 \\
Twill weave & 182.8 & 112 & 54 & 0.30 \\
Satin weave & 185.2 & 113 & 55 & 0.35 \\
\hline
\end{tabular}


Table 2

Process parameters and their levels

\begin{tabular}{lcccc}
\hline & & \multicolumn{3}{c}{ Levels } \\
\cline { 3 - 5 } Numerical factors & Labels & Low & Medium & High \\
\cline { 3 - 5 } & & -1 & 0 & +1 \\
\hline Pressure $\left(\mathrm{kg} / \mathrm{cm}^{2}\right)$ & $\mathrm{A}$ & 1 & 1.5 & 2 \\
Time $(\mathrm{s})$ & $\mathrm{B}$ & 60 & 90 & 120 \\
Concentration $(\%)$ & $\mathrm{C}$ & 0.5 & 1 & 1.5 \\
\hline
\end{tabular}

Table 3

Experimental results of Box-Behnken analysis

\begin{tabular}{ccccccccc}
\hline Run & A & B & C & $\begin{array}{c}\text { Weight } \\
\text { gain }(\%)\end{array}$ & $\begin{array}{c}\text { Tenacity } \\
(\mathrm{KPa})\end{array}$ & $\begin{array}{c}\text { Flexural rigidity } \\
(\mathrm{mg} / \mathrm{cm})\end{array}$ & $\begin{array}{c}\text { Tearing } \\
\text { force }(\mathrm{N})\end{array}$ & $\begin{array}{c}\text { Warp way } \\
\text { shrinkage }(\%)\end{array}$ \\
\hline 1 & 1.5 & 90 & 1 & 1.90 & 209.65 & 688.13 & 11.76 & 10 \\
2 & 1 & 60 & 1 & 1.42 & 213.70 & 754.68 & 10.13 & 7.5 \\
3 & 2 & 90 & 1.5 & 1.80 & 209.56 & 979.78 & 9.94 & 7.5 \\
4 & 1 & 120 & 1 & 1.57 & 215.50 & 900.38 & 9.36 & 10 \\
5 & 2 & 60 & 1 & 1.44 & 196.21 & 825.38 & 10.34 & 7.5 \\
6 & 1.5 & 120 & 1.5 & 2.19 & 219.38 & 754.68 & 9.81 & 7.5 \\
7 & 2 & 90 & 0.5 & 0.82 & 195.87 & 688.13 & 10.93 & 10 \\
8 & 1.5 & 90 & 1 & 1.41 & 221.19 & 625.61 & 9.49 & 7.5 \\
9 & 1 & 60 & 1 & 0.42 & 186.30 & 754.68 & 10.8 & 7.5 \\
10 & 1.5 & 90 & 1 & 1.37 & 190.70 & 688.13 & 9.73 & 7.5 \\
11 & 1 & 90 & 0.5 & 0.61 & 208.59 & 754.68 & 9.47 & 7.5 \\
12 & 1.5 & 90 & 1 & 1.14 & 207.88 & 754.68 & 10.21 & 10 \\
13 & 1.5 & 120 & 0.5 & 0.46 & 191.86 & 688.13 & 9.97 & 7.5 \\
14 & 1.5 & 60 & 0.5 & 1.05 & 214.39 & 567.00 & 10.49 & 10 \\
15 & 1 & 90 & 1.5 & 1.60 & 201.55 & 512.17 & 10.27 & 7.5 \\
16 & 1.5 & 60 & 1.5 & 1.03 & 216.28 & 754.68 & 10.4 & 7.5 \\
17 & 1.5 & 90 & 1 & 1.33 & 194.70 & 825.38 & 10.48 & 7.5 \\
\hline
\end{tabular}

Table 4

Experimental results obtained under optimized conditions

\begin{tabular}{lcccccccc}
\hline Sample & A & B & C & $\begin{array}{c}\text { Weight gain } \\
(\%)\end{array}$ & $\begin{array}{c}\text { Tenacity } \\
(\mathrm{KPa})\end{array}$ & $\begin{array}{c}\text { Flexural rigidity } \\
(\mathrm{mg} / \mathrm{cm})\end{array}$ & $\begin{array}{c}\text { Tearing } \\
\text { force }(\mathrm{N})\end{array}$ & $\begin{array}{c}\text { Warp way } \\
\text { shrinkage }(\%)\end{array}$ \\
\hline Plain weave & 2 & 120 & 1.5 & 2.20 & 219.12 & 754.68 & 9.81 & 7.5 \\
Twill weave & 2 & 120 & 1.5 & 3.06 & 210.68 & 3306.74 & 11.96 & 7.5 \\
Satin weave & 2 & 120 & 1.5 & 2.43 & 208.91 & 3493.88 & 14.15 & 10 \\
\hline
\end{tabular}

\section{Optimization}

Optimization was done for plain weave and the optimized conditions (pressure of $2 \mathrm{~kg} / \mathrm{cm}^{2}$, time of 120 seconds and concentration of $1.5 \mathrm{~W} / \mathrm{V} \%$ ) achieved for maximum desirability (1) were used for the treatment of the other weaves.

\section{Measurements}

The change in the crystallinity of cellulose before and after treatment was determined by X-ray diffraction (PANalytical). Measurements were conducted on a diffractometer equipped with a $\mathrm{Cu} \mathrm{K} \alpha$ radiation source. A $2 \theta$ range from $10^{\circ}$ to $50^{\circ}$, at increments of $0.02^{\circ}$ and a $2^{\circ} \mathrm{min}^{-1}$ scanning speed, was used. The equatorial diffraction profile was detected using an X-ray goniometer with symmetric reflection geometry. ${ }^{2}$ The crystallite size D was estimated using Scherrer's equation: ${ }^{11}$

$\mathrm{D}=\lambda / \beta \cdot \cos \theta$

where $\lambda=1.5418 \AA$, $\beta=$ full width at height maximum (FWHM), $\theta=$ Bragg's angle.

An Agilent Technologies Carry 630 Spectrometer was used, in the wavenumber range of $400-4000 \mathrm{~cm}^{-1}$, for the FTIR analysis of untreated cotton fabric and ACCs. The amount of dissolved cellulose taken up during the treatment was determined from the difference in sample mass before and after the treatment, and expressed as percentage of initial mass. Similarly, warp shrinkage was measured before and after the treatment, and expressed as percentage of initial length. The mechanical properties of the ACCs were measured according to ASTM D5035, in a 
universal testing machine (Aimil), and ASTM D2261 static tear method was used for the measurement of tearing strength.

At least five replicates were measured for each sample. Flexural rigidity tests were carried out in warp direction, on a Shirley Stiffness Tester according to B.S. 3356:1961. Each specimen was tested four times, at each end and again with the strip turned over. Surface images of untreated and treated fabrics at different magnifications were captured using SEM (Zeiss EVO 50). ${ }^{10}$

\section{RESULTS AND DISCUSSION $\mathrm{X}$-ray diffraction}

The equatorial diffraction profiles of (a) the all-cellulose composite, (b) cotton fabric and (c) matrix cellulose are shown in Figure 1. The general shape of this diffractogram is in agreement with those reported in the literature. The reflection peaks at $2 \theta$ angles of $16^{\circ}$ and $22^{\circ}$ are observed for all ACCs; these patterns represent cellulose I, containing two distinct crystalline forms, cellulose $\mathrm{I} \alpha$ (triclinic) and cellulose $\mathrm{I}_{\beta}$ (monoclinic). ${ }^{11}$ The peak at $22^{\circ}$ corresponds to the I200 plane lattice, representing both crystalline and amorphous material, while the diffraction at $18.76^{\circ}$ represents only the amorphous part. ${ }^{12}$ Not much crystal modification is observed in the ACCs. On the other hand, the matrix cellulose is converted into the noncrystalline phase through dissolution and resolidification. ${ }^{13}$ The degree of crystallinity (Xc\%) and the crystallite size were calculated and listed in Table 5, revealing a slight increase in both the degree of crystallinity and the crystallite size of the composite fabric. The change in the crystal

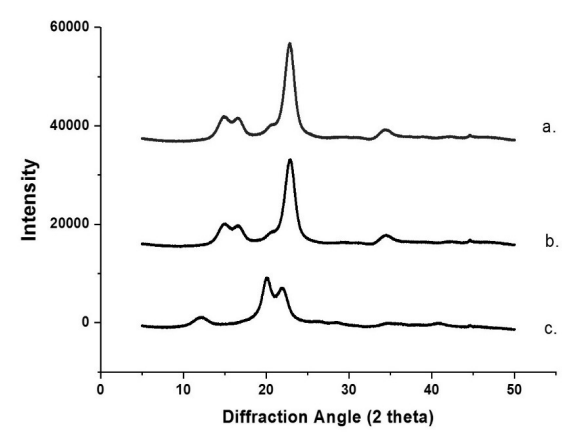

Figure 1: Equatorial diffraction profiles of (a) allcellulose composite, (b) cotton fabric and

(c) matrix cellulose size and degree of crystallinity of the ACC may be due to recrystallization of cellulose during composite formation and the removal of some crystal defects. ${ }^{9}$

\section{FTIR analysis}

The FTIR spectra of the twill all-cellulose composite (a) and untreated twill fabric (b) are shown in Figure 2. Twill fabric was used because of the maximum weight gain, among the three types of fabrics investigated in this study. A peak is observed in the region of $3100-3300 \mathrm{~cm}^{-1}$, which corresponds to strong - $\mathrm{OH}$ stretching and flexural vibration of intra- and inter-molecular hydrogen bonds of cellulose. ${ }^{14}$ The bands observed at $2904 \mathrm{~cm}^{-1}, 2338 \mathrm{~cm}^{-1} 1746 \mathrm{~cm}^{-1}, 1428$ $\mathrm{cm}^{-1}$ and $1315 \mathrm{~cm}^{-1}$ belong to $-\mathrm{CH}$ stretching in aliphatic group, $-\mathrm{CH}$ stretching in aromatic methoxyl groups, $-\mathrm{C}=\mathrm{O}$ stretching, $-\mathrm{C}-\mathrm{C}$ symmetric stretching and $-\mathrm{CH}$ bending, respectively. ${ }^{2,14,15}$ The peak corresponding to the $\mathrm{CH}$ stretching at $2904 \mathrm{~cm}^{-1}$ is less intense in the case of ACC $\left(2896 \mathrm{~cm}^{-1}\right)$, which may be due to the reduction of cellulosic $-\mathrm{CH}_{2} \mathrm{OH}$ groups with the addition of matrix. The signal emerging at $2896 \mathrm{~cm}^{-1}$ corresponds to cellulose II (regenerated cellulose), indicating the inclusion of cellulose II in the fabric structure. ${ }^{11,16}$ The presence of cellulose II may also be due to exposure of cellulose to alkaline conditions. There is a shift in the signal peak from $2338 \mathrm{~cm}^{-1}$ to $2317 \mathrm{~cm}^{-1}$ and from $1746 \mathrm{~cm}^{-1}$ to $1797 \mathrm{~cm}^{-1}$. The twill allcellulose composite indicates that the treatment determines marginal structural changes caused by the add-on amount of viscose matrix.

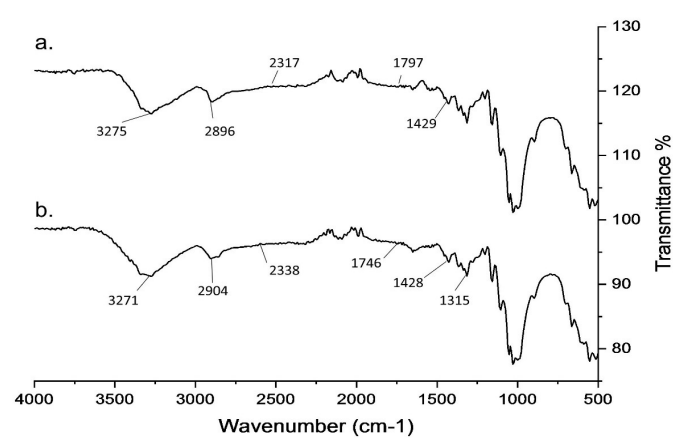

Figure 2: FTIR spectra of (a) ACC and

(b) cotton fabric 
Table 5

Degree of crystallinity and crystallite size of ACCs and cotton fabric

\begin{tabular}{lcc}
\hline Sample & Degree of crystallinity (Xc \%) & Crystallite size (nm) \\
\hline Untreated cotton fabric & 63.90 & 4.32 \\
ACC & 65 & 4.49 \\
\hline
\end{tabular}
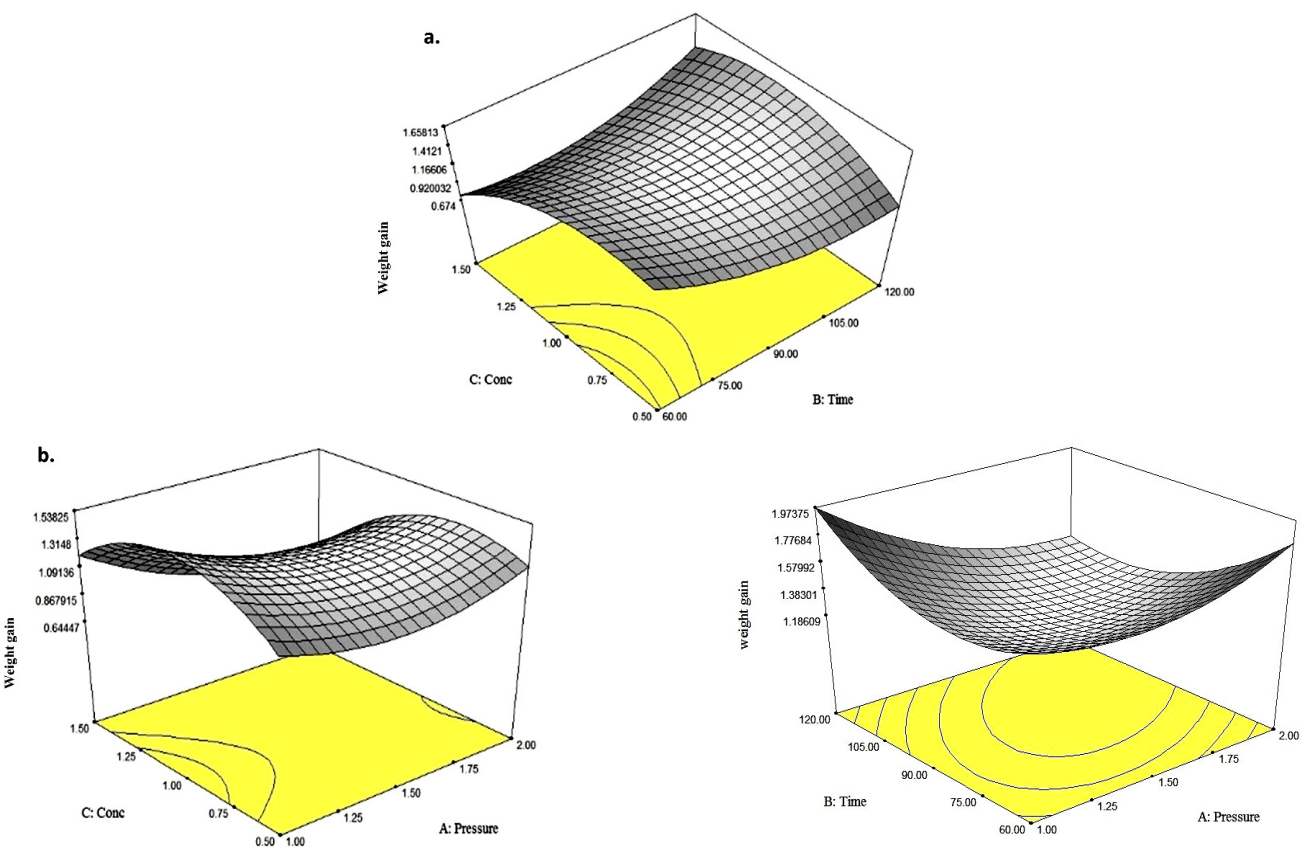

Figure 3: Influence of different process parameters on weight gain of composite; (a) concentration $v s$ time,

(b) concentration $v s$ pressure and (c) time $v s$ pressure

\section{Effect of process parameters on weight gain}

The influence of process parameters, such as pressure, time and concentration of the cellulose solution, on weight gain was investigated by employing the Box-Behnken design and response surface methodology.

The model equation in coded unit is as follows:

Weight gain $=+1.22-0.12 \mathrm{~A}-0.045 \mathrm{~B}-0.13 \mathrm{C}+$ $0.19 \mathrm{~A}^{2}+0.26 \mathrm{~B}^{2}-0.35 \mathrm{C}^{2}-0.22 \mathrm{AB}-0.14 \mathrm{AC}+$ $0.30 \mathrm{BC}$

The effect of pressure and time on the weight gain of ACC at constant cellulose solution concentration is shown in Figure 3. Weight gain increases with the increase in dipping time (Fig. 3 a) and pressure (Fig. 3 b). It may be explained by an increase in cellulosic interaction and the impregnation of the solution into the substrate. ${ }^{17,18}$ A maximum weight gain of $1.97 \%$ was achieved at maximum time and minimum pressure. This may be due to an increase in cellulose interaction with increasing dipping time and low pressure. However, the concentration of the cellulose solution does not influence weight gain much within the investigated range.

\section{Mechanical properties}

The mechanical properties of the fabrics and the composites are summarized in Table 6 . Compared to the untreated fabric, there is a marginal increase in tensile strength, a significant increase in elongation at break and a significant decrease in the modulus of ACCs for all types of weaves.

After the treatment, there are no significant changes in tensile strength, may be because of less cellulose add-on on the fabric. There is a definite increase in elongation (\%) and a decrease in Young's modulus of the ACC due to the interaction of the cellulose solution with the amorphous area of the substrate. ${ }^{19}$ The cellulose solution is alkaline in nature, which increases the intermolecular spacing by breaking bonds, probably leading to disorientation of the molecules in the amorphous area of the cellulose, thus contributing to an increase in elongation and reduction of modulus values of the fabric after the 
NASHRAH H. KIDWAI et al.

treatment. ${ }^{16}$ As shown in Table 6 , the decrease in Young's modulus observed after the treatment may be caused by the cellulose solution that interacts with the amorphous area of the substrate upon the treatment, which, in turn, absorbs solvent and swells, thus giving more space for the movement. ${ }^{20}$

\section{Tearing strength}

Table 7 shows the tearing force of each sample before and after the treatment, with the corresponding warp shrinkage in the composite. Comparing the warp way tearing strength of different ACCs, satin having long floats has higher tear strength $(20.37 \mathrm{~N})$ than that of the plain fabric with the shortest float $(11.61 \mathrm{~N})$. The type of fabric weave has an important effect on its tearing strength. Weave affects the ease of thread slippage and the number of threads breaking together, as well as the float length. ${ }^{17}$ There is maximum reduction in tearing strength after the treatment in the case of satin ACC. Warp shrinkage and the add-on of cellulose on the fabric influences the loss in strength. Both the shrinkage and the deposition of cellulose on the yarn surfaces and interstices influence the mobility of the yarn during the tearing test. ${ }^{21}$ In the case of plain fabric, the change in mobility is minimum, while it is maximum in the case of satin fabric, which is reflected in the tearing test results of the composite. Thus, both the weave effect and warp shrinkage reduce the tearing strength in composites after the treatment.

\section{Flexural rigidity}

The mean bending length and flexural rigidity values of both untreated and treated fabrics are shown in Table 8.

Table 6

Mechanical properties of cotton fabrics and their respective ACCs

\begin{tabular}{lcccc}
\hline \multirow{2}{*}{ Sample } & & $\begin{array}{c}\text { Tensile strength } \\
(\mathrm{KPa})\end{array}$ & $\begin{array}{c}\text { Elongation at break } \\
(\%)\end{array}$ & $\begin{array}{c}\text { Young's modulus } \\
(\mathrm{MPa})\end{array}$ \\
\cline { 2 - 5 } Plain & Fabric & 216.28 & 18.04 & 7.32 \\
& ACC & 219.12 & 26.98 & 4.22 \\
\hline \multirow{2}{*}{ Twill } & Fabric & 208.40 & 16.13 & 8.63 \\
& ACC & 210.68 & 25.55 & 4.67 \\
\multirow{2}{*}{ Satin } & Fabric & 203.88 & 13.86 & 11.71 \\
& ACC & 208.91 & 17.41 & 5.40 \\
\hline
\end{tabular}

Table 7

Tearing strength (warp way) of fabrics and ACCs

\begin{tabular}{lcccc}
\hline Sample & $\begin{array}{c}\text { Tearing strength } \\
(\mathrm{N}) \text { (before) }\end{array}$ & $\begin{array}{c}\text { Tearing } \\
\text { strength (after) }\end{array}$ & $\begin{array}{c}\text { \% Reduction in } \\
\text { tearing strength }\end{array}$ & $\begin{array}{c}\text { Warp shrinkage } \\
\text { (after) }(\%)\end{array}$ \\
\hline Plain ACC & 11.61 & 9.81 & 15.50 & 7.5 \\
Twill ACC & 16.79 & 11.96 & 28.77 & 7.5 \\
Satin ACC & 20.37 & 14.15 & 30.54 & 10 \\
\hline
\end{tabular}

Table 8

Flexural rigidity of fabrics and ACCs

\begin{tabular}{lccccc}
\hline $\begin{array}{l}\text { Sample } \\
\text { type }\end{array}$ & $\begin{array}{c}\text { Bending } \\
\text { length }(\mathrm{cm})\end{array}$ & $\begin{array}{c}\text { Flexural rigidity } \\
(\mathrm{mg} / \mathrm{cm})\end{array}$ & $\begin{array}{c}\text { Bending } \\
\text { length }(\mathrm{cm})\end{array}$ & $\begin{array}{c}\text { Flexural rigidity } \\
(\mathrm{mg} / \mathrm{cm})\end{array}$ & $\begin{array}{c}\text { \% Decrease } \\
\text { in stiffness }\end{array}$ \\
\cline { 2 - 4 } & \multicolumn{2}{c}{ Before treatment } & After treatment $(\mathrm{ACC})$ & \\
\hline Plain & 3.5 & 900.38 & 3.3 & 754.68 & 16.18 \\
Twill & 5.6 & 3687.94 & 5.4 & 3306.74 & 10.34 \\
Satin & 5.7 & 3889.05 & 5.5 & 3493.88 & 10.16 \\
\hline
\end{tabular}




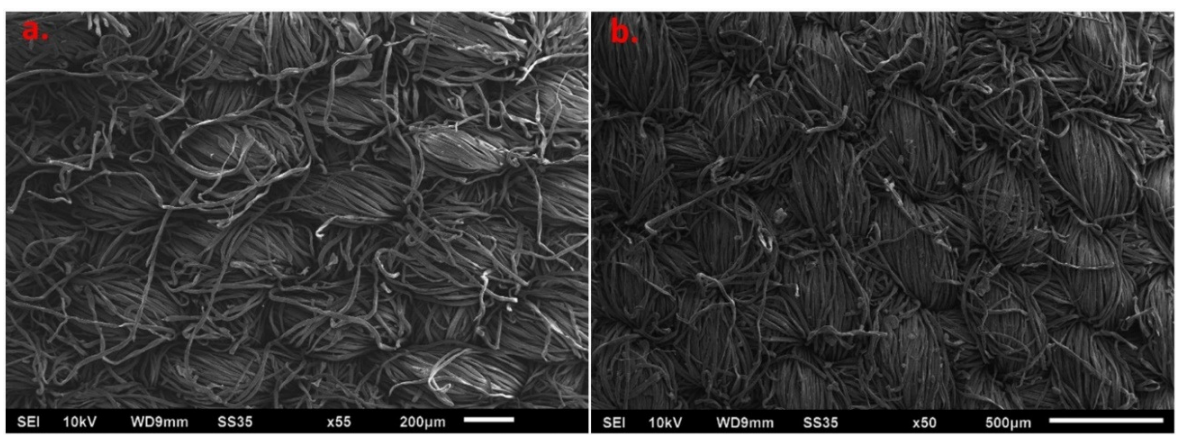

Figure 4: SEM images of (a) cotton fabric and (b) all-cellulose composite

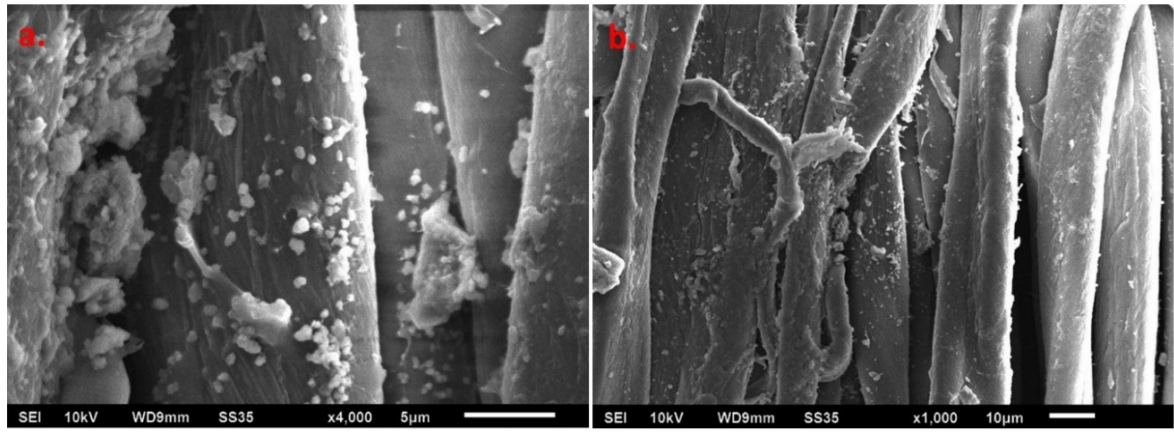

Figure 5: SEM images of ACC at different magnifications, (a) 4000x and (b) 1000x

There is a marginal decrease in fabric stiffness after the treatment in all the cases. This may be explained by the interaction of the cellulose solution with the amorphous area of the substrate during the treatment, which in turn absorbs solvent and swells, thus giving more free space and causing a rearrangement of the molecular zone. A relationship could be established between swelling and shrinkage, as shrinkage occurs in warp direction in the composite after drying. The reason for the decrease in flexural rigidity from plain to satin can be ascribed to the float length of the yarn in the fabric - the lesser is float length, the higher is flexural rigidity.

\section{SEM analysis}

The surface morphology of untreated fabric and ACC is shown in Figure 4. After the treatment (Fig. 4 b), the compactness of the fabric increased, as compared to that of untreated cotton fabric (Fig. 4 a). This may be due to swelling of fibres during the alkali treatment, when pressure was applied while the fabric passed through the padding mangle. ${ }^{9}$ SEM images of ACC at different magnifications are shown in Figure 5. As the cotton fibre undergoes treatment with dissolved cellulose solution in $\mathrm{NaOH} /$ urea solvent, ${ }^{22}$ the presence of coagulated cellulose on the yarn surface can be observed. These images clearly show the adhesion of coagulated cellulose to the cotton fabric.

\section{CONCLUSION}

All-cellulose composites of woven cotton fabric and dissolved cellulose have been successfully prepared, in which low DP cellulose was used as matrix and high DP cellulose, in fabric form, was used as filler. The processing parameters, i.e. pressure, time and concentration of the cellulose solution, influence the mechanical properties of ACCs through their effect on crystallinity, tensile strength, elongation and tearing strength of the composites. After the treatment, a marginal change in tenacity may be due to a lower amount of percentage add-on. The crystallinity and crystallite size marginally improved after the treatment. The interaction of low and high DP celluloses is observed in the SEM images. The woven structure is compacted after the treatment due to the add-on of coagulated cellulose onto the fibre surface. There is a pronounced effect of fabric structure on the properties of the resultant composites. The elongation percentage significantly increased by around $50 \%$ in the case of plain ACC, $58.40 \%$ for twill ACC and $25.61 \%$ for satin ACC after the treatment. However, the tearing strength of the composites reduced by $15.50 \%, 28.77 \%$ and 
$30.54 \%$ for plain, twill and satin ACCs, while stiffness reduced by $16.18 \%, 10.34 \%$ and $10.16 \%$, respectively. A limitation of the process consists in the dissolution of cellulose in aqueous $\mathrm{NaOH}$ at a low temperature $\left(-12^{\circ} \mathrm{C}\right)$ and the concentration to maintain the solubility and stability of the solution. The study revealed that the mechanical properties of ACCs are governed by the selection of an appropriate cellulose source and suitable process parameters.

\section{REFERENCES}

1 T. Nishino, I. Matsuda and
Macromolecules, $\quad \begin{aligned} & \text { 37, } \\ & 7683\end{aligned} \quad \begin{array}{r}\text { Hirao, } \\ \text { (2004), }\end{array}$ https://doi.org/10.1021/Ma049300h

2 M. J. John and S. Thomas, Carbohyd. Polym., 71, 343 (2008), https://doi.org/j.carbpol.2007.05.040

3 G. F. Davidson, J. Textile Inst. Trans., 25, 174 (1934), https://doi.org/10.1080/19447023408661621

4 J. Cai and L. Zhang, Macromol. Biosci., 5, 5539 (2005), https://doi.org/10.1002/mabi.200400222

5 W. Gindl and J. Keckes, Polymers, 46, 10221 (2005), https://doi.org/10.1016/j.polymer.2005.08.040

6 P. Piltonenet, N. C. Hildebrandt, B. Westerlind, J.P. Valkama, T. Tervahartiala et al., Compos. Sci. Technol., 135, 153 (2016), http://dx.doi.org/10.1016\%2Fj.compscitech.2016.09.02 2

J. Zhou, Polym. Sci., 10, $866 \quad$ (2000), https://doi.org/10.1295/polymj.32.866

8 N. Soykeabkaew, Composites, 40, 321 (2009), https://doi.org/10.1016/j.compositesa.2008.10.021

9 J. C. Duchemin, Compos. Sci. Technol., 69, 1225 (2009),

https://doi.org/10.1016/j.compscitech.2009.02.027

10 T. Huber, J. Mussig, O. Curnow, S. Pang, S. Bickerton et al., J. Mater. Sci., 47, 1171 (2012), https://doi.org/10.1007/s10853-011-5774-3

11 M. Wada and T. Okano, Cellulose, 8, 183 (2001), https://doi.org/10.1023/A:1013196220602

12 A. D. French and M. Santiago, Cellulose, 20, 583 (2013), https://doi.org/10.1007/s10570-012-9833-y
13 T. Nishino and N. Arimoto, Biomacromolecules, 8, 2712 (2007), https://doi.org/10.1021/bm0703416

14 C. J. Chirayil, J. Joy, L. Mathew, M. Mozetic, J. Koetz et al., Ind. Crop. Prod., 59, 27 (2014), https://doi.org/10.1016/j.indcrop.2014.04.020

15 M. Poletto, H. L. Ornaghi Jr. and A. Zattera, Materials, $\quad$ 19, $6105 \quad$ (2014), https://doi.org/10.3390/ma7096105

${ }^{16} \mathrm{H}$. Singh and A. Chatterjee, Cellulose, 9, 2555 (2020), https://doi.org/10.1007/s10570-019-02917-9

17 T. T. Loan, S. Barbora, P. Avinash and T. Peijs, Compos. Sci. Technol., 78, 30 (2013), http://dx.doi.org/10.1016/j.compscitech.2008.03.023

18 C. A. de Carvalho Mendes, F. A. de Oliveira Adnet, M. C. Amorim Moreira Leite, C. Russi Guimarães Furtado and A. M. Furtado de Sousa, Cellulose Chem. Technol., 49, 727 (2015), http://www.cellulosechemtechnol.ro/pdf/CCT910(2015)/p.727-735.pdf

19 M. P. Staiger and T. Huber, in "Encyclopedia of Composites", edited by L. Nicolais and A. Borzacchiello, John Wiley and Sons Inc., $2^{\text {nd }}$ ed., 2012, https://doi.org/10.1002/9781118097298.weoc006

20 H. Jin, C. Zha and L. Gu, Carbohyd. Res., 342, 851 (2007), https://doi.org/10.1016/j.carres.2006.12.023

21 T. P. Tumolva, D. S. Enguero, T. J. C Laus and B. A. Requejo, MATEC Web Conf., 62, 1003 (2016), https://doi.org/10.1051/matecconf/20166201003

22 B. J. Duchemin, A. P. Mathew and K. Oksman, Composites, 40, $2031 \quad$ (2009), https://doi.org/10.1016/j.compositesa.2009.09.013 